\title{
Numerical Simulation and Visualization of Material Flow in Friction Stir Welding via Particle Tracing
}

\author{
N. Dialami ${ }^{\dagger}$, M. Chiumenti ${ }^{\dagger}$, M. Cervera ${ }^{\dagger}$, C. Agelet de Saracibar ${ }^{\dagger}$, \\ J.P. Ponthot ${ }^{*}$ and P. Bussetta ${ }^{*}$ \\ ${ }^{\dagger}$ International Center for Numerical Methods in Engineering \\ (CIMNE), \\ Technical University of Catalonia, UPC BarcelonaTech, \\ Building C1, North Campus \\ C/ Gran Capitán s/n, 08034 Barcelona, Spain \\ *University of Liege \\ LTAS- MN2L, Aerospace \& Mechanical Engineering, Building B52/3, \\ Chemin des Chevreuils, 1; B-4000 Liege, Belgium
}

Corresponding author: Narges Dialami, Tel. (+34) 934016529 /

Fax (+34) 934016517

E-mail addresses: narges@cimne.upc.edu (N. Dialami), michele@cimne.upc.edu (M. Chiumenti), mcervera@,cimne.upc.edu (M. Cervera), agelet@cimne.upc.edu (C. Agelet de Saracibar), JP.Ponthot@ulg.ac.be (J.P. Ponthot),

P.Bussetta@ulg.ac.be (P. Bussetta)

\begin{abstract}
This work deals with the numerical simulation and material flow visualization of Friction Stir Welding (FSW) processes. The 4-th order Runge-Kutta (RK4) integration method is used for the computation of particle trajectories. The particle tracing method is used to study the effect of input process parameters and pin shapes on the weld quality. The results show that the proposed method is suitable for the optimization of the FSW process.
\end{abstract}




\section{Introduction}

Friction Stir Welding is a solid-state joining technique lately found by Thomas et al. [1]. The basic concept of FSW is the following. A shouldered pin rotating at constant rotational speed is inserted into the line between the two plates to be welded. Once the insertion is completed, the pin is moved along the welding line at constant rotating and advancing speeds to form the joint.

Ideally, the pin is designed to disrupt the contacting surfaces of the work-piece, shear the material in front of the tool and move the material behind the tool. The depth of deformation and the tool travel speed are mainly governed by the pin. This serves two primary functions: heating of the work-piece, and moving the material to produce the joint. In general, both the heat and the material transfer depend on the work-piece material properties, tool geometry, and FSW process parameters

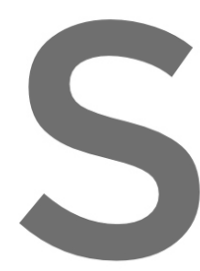

One

During deformatio is achieved
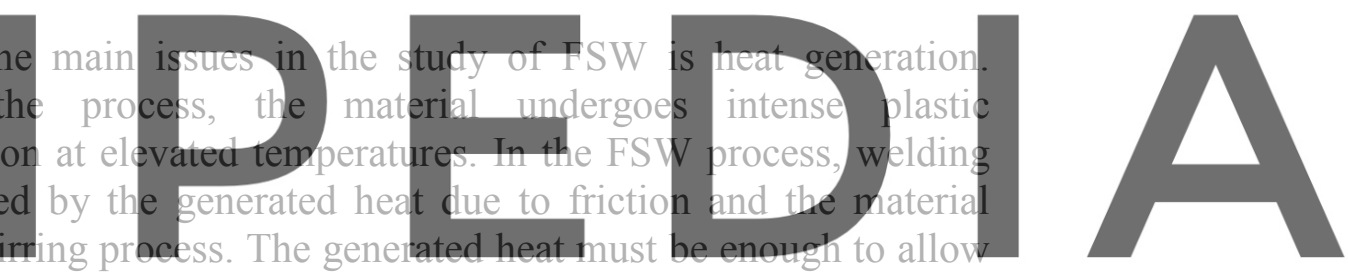

for the material to flow and to obtain a deep heat affected zone

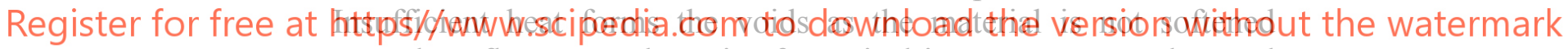
enough to flow properly. It is of practical importance to understand the material flow characteristics for optimal tool design and obtain high structural efficiency welds. The visualization of the material flow is very useful to understand its behavior during the weld. This has led to numerous investigations on material flow behavior during FSW. A method assessing the quality of the created weld by visualization of the joint pattern is advantageous. It can be used to have a pre-knowledge of the appropriate process parameters. However, following the position of the material during the welding process is not an easy task, neither experimentally or numerically.

The experimental material visualization is difficult and needs metallographic tools. In an attempt to better understand FSW, many investigators have used experimental techniques to visualize the 
material flow and to estimate characteristics of FSW. Most of the studies done so far are based on the experimental study of material flow tracing. Two different tracer techniques were used by different researchers for visualization of the material flow. The first was a tracer technique by marker material where a dissimilar material is inserted into the weld line. The second technique was to weld two dissimilar materials with the FSW process and then see the material mixing. The marker materials were different Al-composites [2], [3], [4], steel balls [5], copper foil [6], [7], plasticine and brass rods [8]. The used dissimilar base materials were different magnesium alloys [9], aluminum to copper alloys [10], [11].

Alternatively, establishing a numerical method for the visualization of the material trajectory in order to gain insight to the heat affected zone has been attempted. Computational methods including the finite element method have been used to model the material flow.
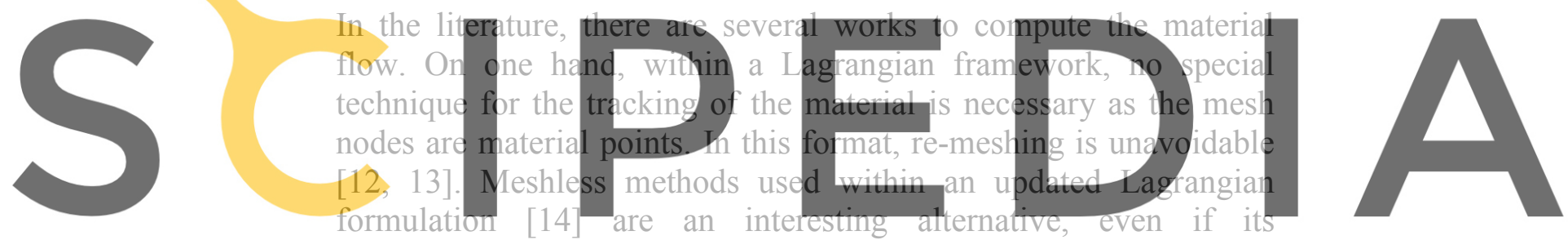

computational cost is usually higher than the classical finite element

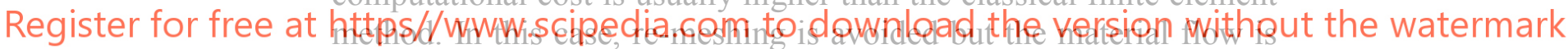

known only at the nodal points. On the other hand, when using an

Eulerian/ALE approach, a specific technique to compute the material trajectories must be implemented. However, the mesh density used for the FSW simulation is not related to the definition of the set of particles used for the visualization of the material flow. Hence, a large number of particles can be used without increasing the computational effort devoted to the simulation of the process itself. Following this approach, the ALE formulation together with a splitting method is proposed in [15] to analyze different phases of FSW process. In [16] an Eulerian formulation together with a simple mesh moving technique is used to avoid mesh distortions and reducing the computing time due to the ALE technique. 
In this work, a numerical particle tracing technology is proposed to study the extent of material stirring during the FSW process and to study the weld quality.

The outline of the chapter is as follows. Firstly the particle tracing technique is described using a RK4 integration technique for the computation of particle trajectory. Afterwards, the proposed method is applied to different examples in order to study the quality of the final joint for different process parameters and pin shapes. Finally some conclusions are drawn.

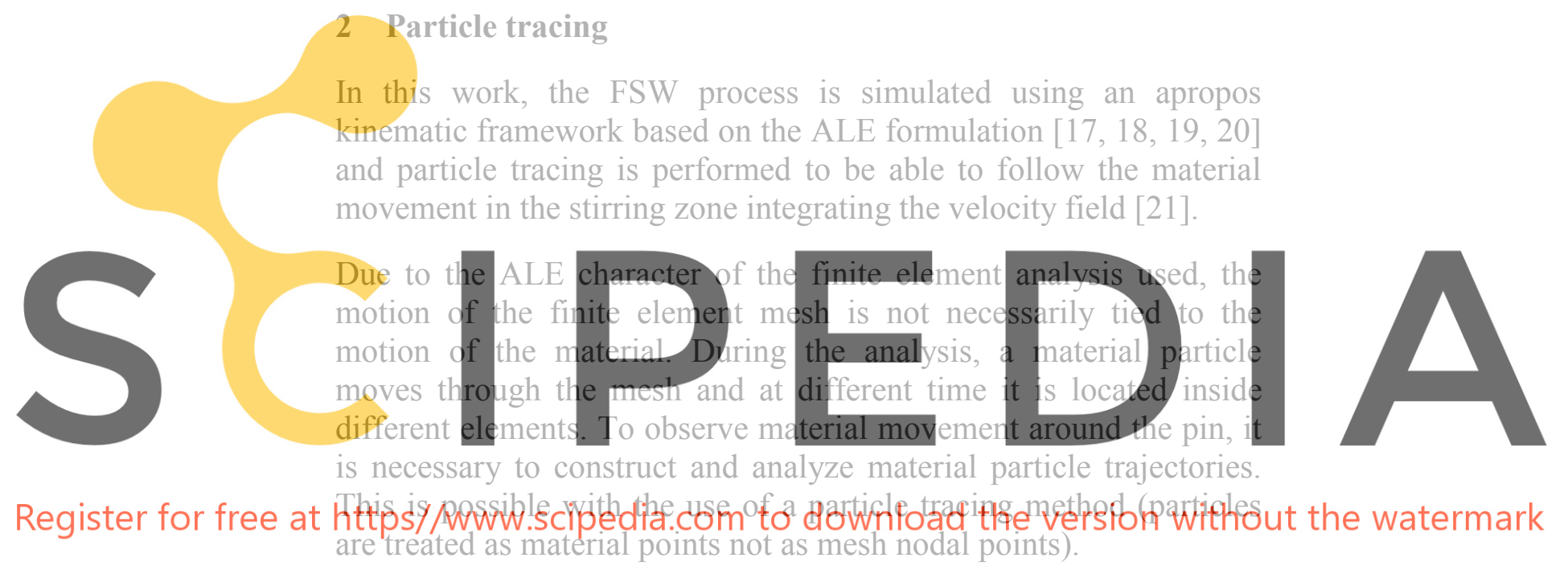

Particle tracing is a method used to simulate the motion of material points, following their positions at each time-step of the analysis. This method can be naturally applied to the study of the material flow in the welding process. In the Lagrangian framework, as the mesh nodes represent the material points, the trajectories are the solution of the governing system of equations. When using an Eulerian or ALE framework the solution does not gives directly information about the material points. However, the obtained velocity field can be used to get an insight of the extent of material mixing during the weld.

In this method, firstly, a set of points representing the material points (tracers) are distributed in the domain and then, a Lagrangian 
Ordinary Differential Equation (ODE) for the computation of material displacement at a post-process level must be solved. Each particle's path is followed in time integrating the following ODE equation:

$$
\frac{D(\mathbf{X}(t))}{D t}=\mathbf{V}(\mathbf{X}(t), t)
$$

Integrating (1) yields:

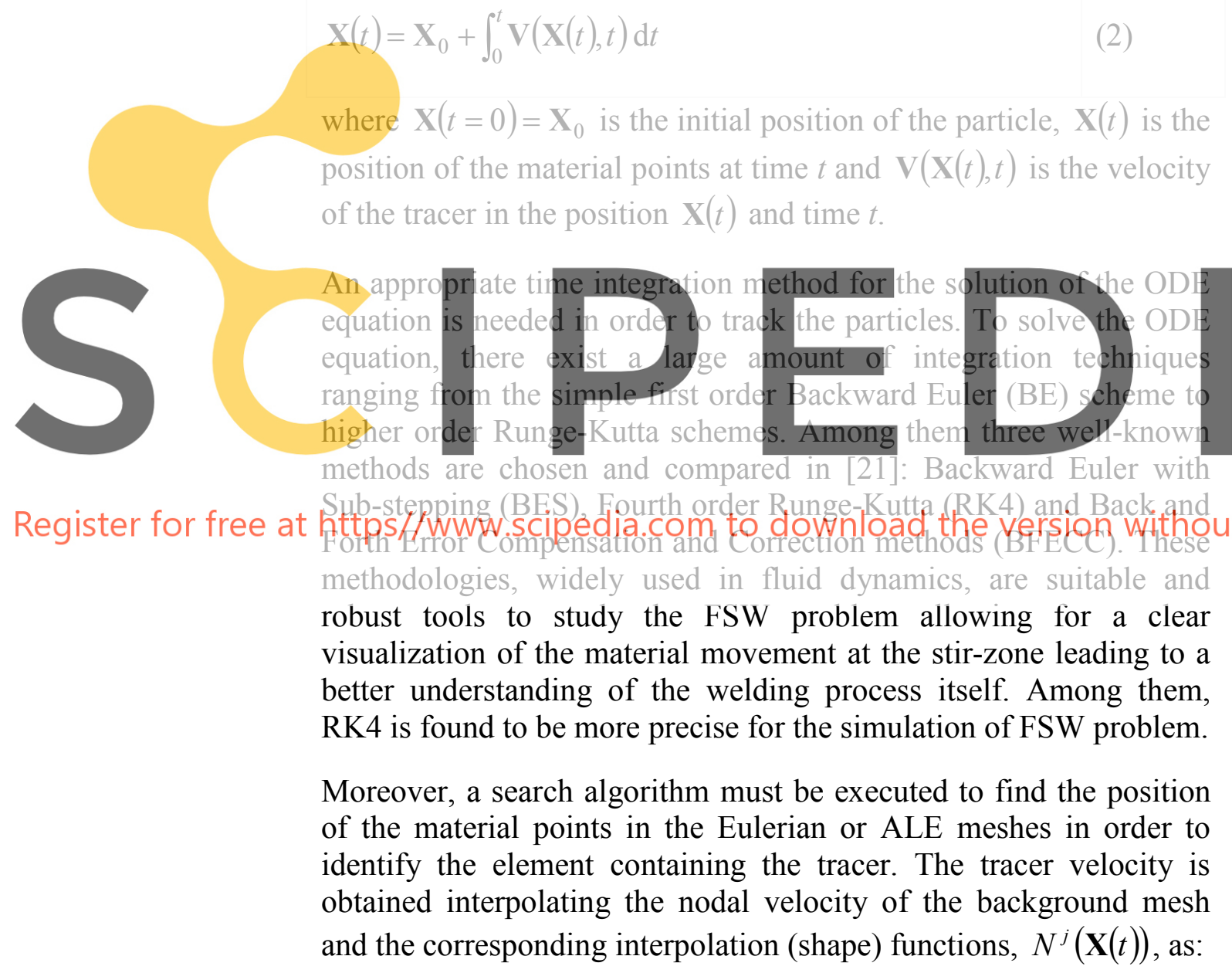




$$
\mathbf{V}(\mathbf{X}(t), t)=\sum_{j=1}^{n} \mathbf{v}_{j}(t) \cdot N^{j}(\mathbf{X}(t))
$$

where the velocity field, $\mathbf{v}_{j}(t)$, is known at each node, $j$, of the finite element mesh representing the domain at any time, $t$, of the analysis.

\subsection{RK4 method}

According to the forth-order accurate RK4 method, the particle position at time-step $n+1$ is computed from the advection of the initial position by four weighted incremental displacement at intermediate time-steps.

$$
\boldsymbol{X}_{n+1}=\boldsymbol{X}_{n}+\frac{1}{6}\left(\Delta \boldsymbol{X}^{(1)}+2 \Delta \boldsymbol{X}^{(2)}+2 \Delta \mathbf{X}^{(3)}+\Delta \mathbf{X}^{(4)}\right)
$$
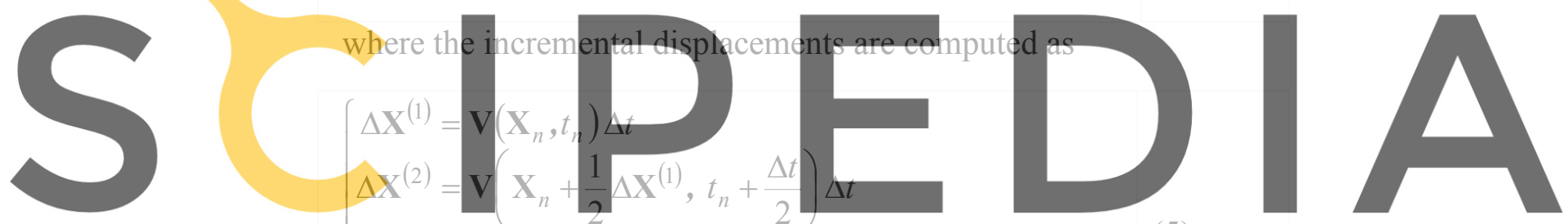

Register for free at https / /WWW'scipedfa.com to download the version without the watermark $\Delta \mathbf{X}^{(4)}=\mathbf{V}\left(\mathbf{X}_{n}+\Delta \mathbf{X}^{(3)}, t_{n}+\Delta t\right) \Delta t$

The RK4 method is a 4-th order method, meaning that the error per step is $O\left(\Delta t^{5}\right)$, while the total accumulated error is $O\left(\Delta t^{4}\right)$. The RK4 method is an appropriate choice as it can integrate exactly a circular trajectory, a standard particle path in FSW.

The nodal velocity field, $\mathbf{v}_{n+1}^{t_{n}+\frac{\Delta t}{2}}(t)$, corresponding to the mid-time step $t_{n}+\frac{\Delta t}{2}$ is obtained as: 
$\mathbf{v}_{n+1}^{t_{n}+\frac{\Delta t}{2}}(t)=\frac{\mathbf{v}_{n}+\mathbf{v}_{n+1}}{2}$

where $\mathbf{v}_{n}$ and $\mathbf{v}_{n+1}$ are the nodal velocity fields at times $t_{n}$ and $t_{n+1}$, respectively.

\section{Examples}

The material flow during FSW is complex and the understanding of deformation process is limited. It is important to point out that there are many factors that can influence the material flow during FSW. These factors include tool geometry, welding parameters, material types, work-piece temperature, etc.

The proposed method is used to investigate the effect of these factors on the qualification of the final weld. The first example

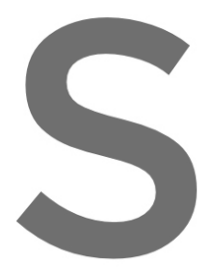

studies
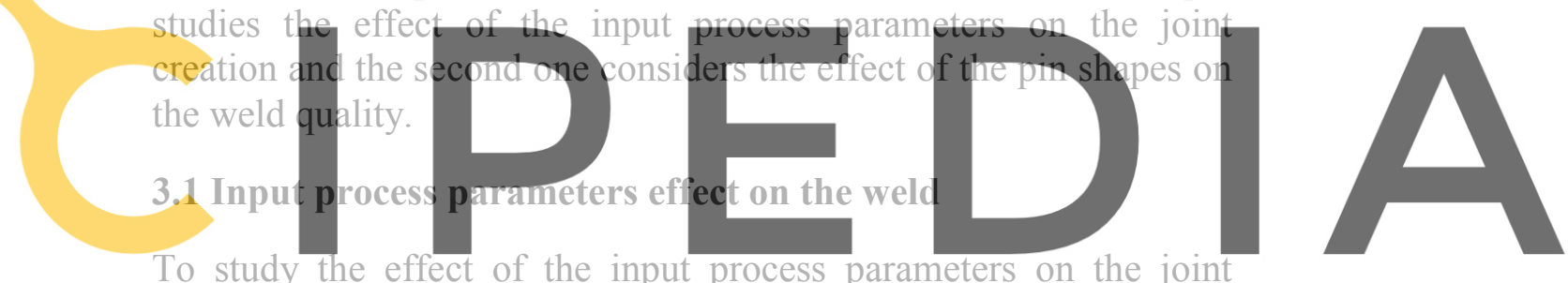

Register for free at

mulity a 2D example is considered. The model is a transversal cut ftes/fwww scipedia fom to download the version without the watermark

The cut represents the mid-section of the real threaded pin. The contact condition between the pin and the work-piece (AA2195-T8) is considered to be perfect sticking. Process parameters are the same as in the experiment: welding speed $\mathrm{V}_{\mathrm{s}}=5.0833 \mathrm{~mm} / \mathrm{s}$ and rotational speed $\mathrm{V}_{\mathrm{r}}=500 \mathrm{rpm}$. A Sheppard-Wright constitutive model is used [21].

A set of $100 \times 150$ particles in a shape of a $20 \times 30 \mathrm{~mm}^{2}$ rectangle at their initial position is located right in front of the pin. The whole model is discretized with a mesh of 4986 triangular elements. The problem is solved using the $v / p$ mixed formulation stabilized by the OSS stabilization method [17, 18, 19]. The RK4 time integration method is applied for the solution of the particle tracing problem. The model has been already validated in the authors' work [21]. 
To study the effect of the input parameters and to gain an insight of the ratio influence between advancing and rotational velocities, two "limit cases" and the original case problem with the same boundary condition and material properties and the velocity fields: (a) $\mathrm{Vs}=$ $5.0833 \mathrm{~mm} / \mathrm{s} ; \mathrm{Vr}=0 \mathrm{rpm}$, (b) $\mathrm{Vs}=0.50833 \mathrm{~mm} / \mathrm{s} ; \mathrm{Vr}=500 \mathrm{rpm}$ and (c) $\mathrm{Vs}=5.0833 \mathrm{~mm} / \mathrm{s} ; \mathrm{Vr}=500 \mathrm{rpm}$ are analyzed. Apart from the original problem, one case where the rotational velocity is zero and the other case where the advancing velocity is very small (advancing velocity cannot be zero) are considered.

Studying these three cases reveals some characteristics of the material flow pattern. Figure 1 shows the particles pattern after joint creation and the velocity streamlines for these three sets of velocity. Case (c) is the original problem [21]. It shows an initially straight transverse set of particles that has been welded through. Note that the material moves backward in a curve, and a thin zone is swept forward on the advancing side, as seen in the predicted particle

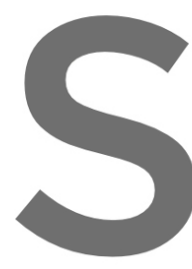
tracks.
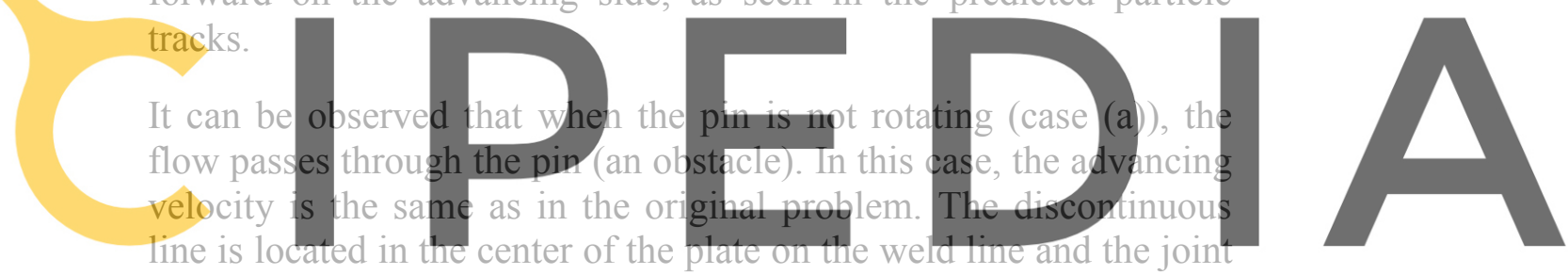

is not created.

Register for free at https//www.scipedia.com to download the version without the watermark

In case (b), the rotational velocity of the pin is the same as the

original problem but the advancing velocity is 10 times smaller.

Even though case (b) and case (c) show the same velocity contour field, streamlines in case (b) represent more material rotation around the pin. The reason is the much bigger ratio between the rotational and advancing velocities than in the case (c). Moreover, via particle tracing technique the effect of the input parameters on the weld quality can be observed. It is shown that when the advancing velocity is much smaller than the rotational one, the joint is defective and non-qualified and the weld line is not located at the center line.

By comparing the three cases, it can be concluded that the ratio between the rotational and advancing velocities is crucial to obtain a 
qualified joint. They cannot be arbitrary selected. Particularly, a very low advancing velocity comparing with the rotational one does not lead to a qualified joint.
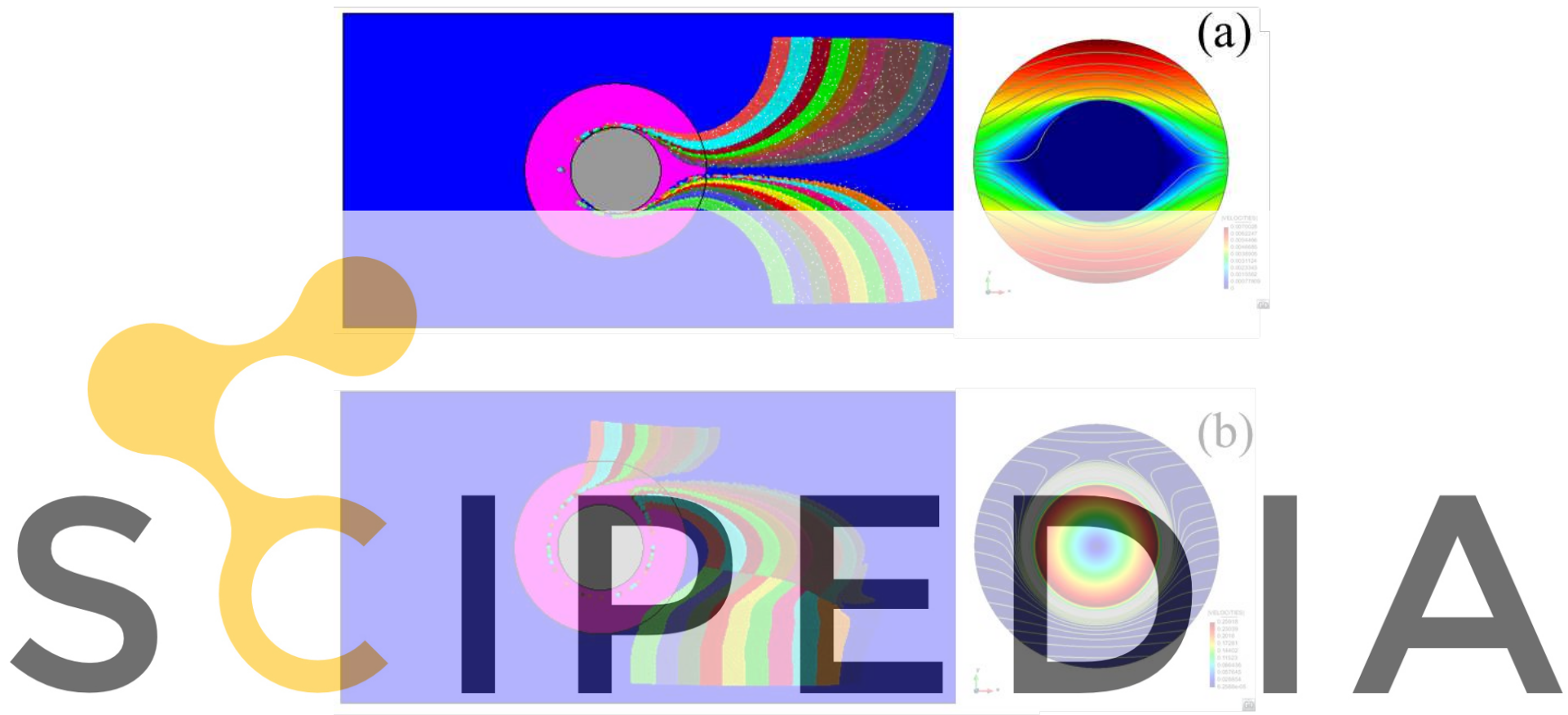

Register for free at https//www.scipedia.com to download the version without the watermark
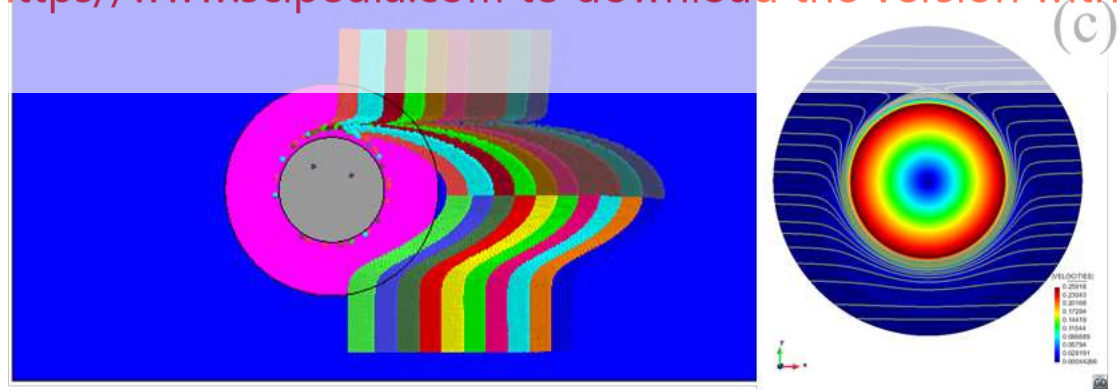

Figure 1: Creation of the weld joint with different input parameters (a) $V s=5.0833 \mathrm{~mm} / \mathrm{s}, \mathrm{Vr}=0 \mathrm{rpm}$; (b) $\mathrm{Vs}=0.50833 \mathrm{~mm} / \mathrm{s}, \mathrm{Vr}=500 \mathrm{rpm}$; (c) $V s=5.0833 \mathrm{~mm} / \mathrm{s}, \mathrm{Vr}=500 \mathrm{rpm}$. 


\subsection{Different pin shapes effect on the weld}

The second example investigates the effect of different pin shapes on the joint creation using the proposed particle tracing method. Different types of pin shape are considered and shown in Figure 2 including (a) triflute; (b) trivex; (c) circular; (d) triangular. The pins are generated from an originalyl circular section of $10 \mathrm{~mm}$ diameter (Figure 2). The trivex pin design is approximately triangular; the three points of the pin form an equilateral triangle and are connected by convex sides. The triflute pin shape is obtained from an original circular section removing three circular segments.

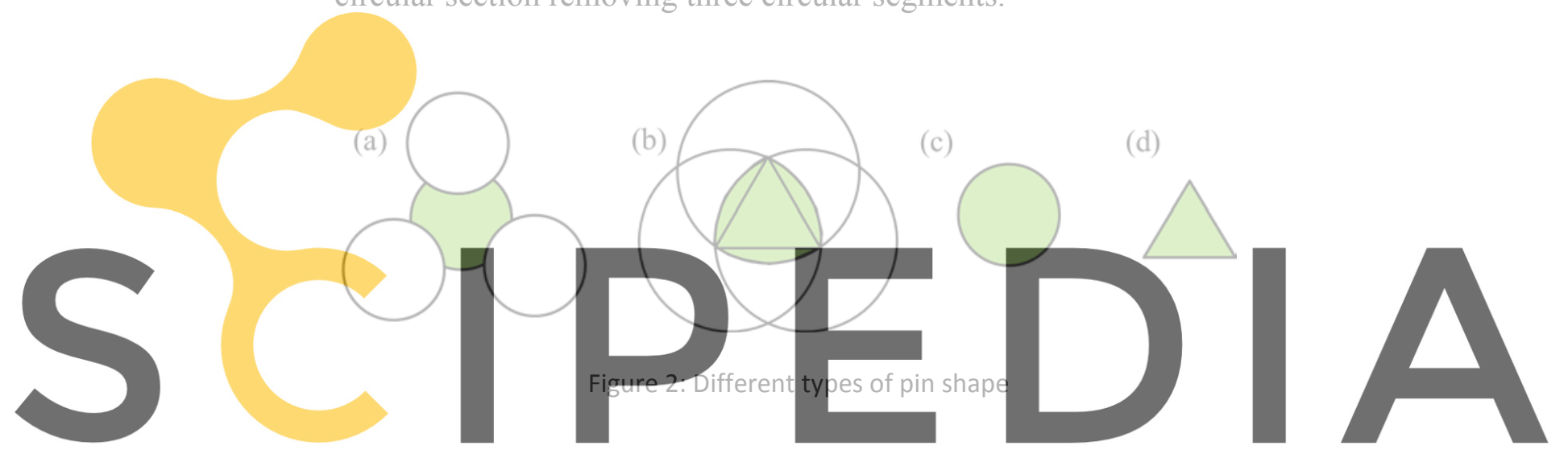

A square domain of $80 \times 80 \mathrm{~mm}^{2}$ is considered with a circular heat

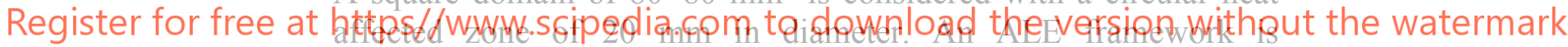
considered in the heat affected zone and the rest of the circular domain is defined in the Eulerian framework. The RK4 integration technique is used for the solution of the particle tracing problem.

In a first step, the problem is analyzed under the stick condition. Figure 3 illustrates the temperature contour fields obtained together with the streamlines. The streamlines show that: voids are created using the pins with sharp corners such as trivex and especially triangular pins; the circular and triflute pin present similar streamlines taking into account that the stick condition is assumed. Note that the triflute shows significantly more material being captured and taken around the tool more than once, whereas the trivex struggles to fill the space behind the tool on the advancing side. This is therefore consistent with the generation of a void in the 
wake of a trivex tool. The triflute pin has a high swept rate due to the segments and a tool design with a higher swept rate reduces the voids.
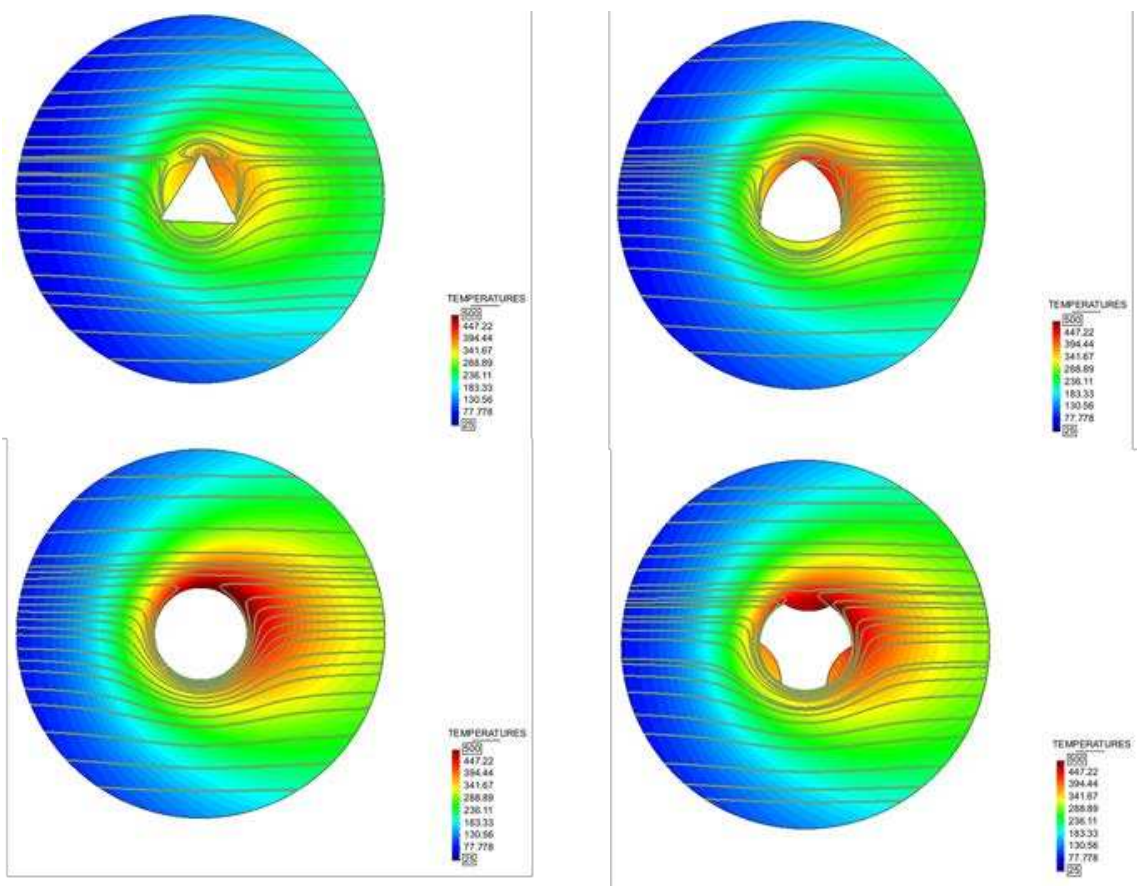

Figure 3: Temperature field and streamlines obtained from different pin shapes

It can be observed that the generated heat is greater for the triflute and the circular pin than for the trivex and the triangular pins as in the stick condition more material move together with the pins.

The pressure contour field is illustrated in Figure 4. Pins with sharper corners have higher maximum pressure value as for triangular and trivex pins than the ones with convex sides as for circular and triflute pins. However the maximum pressure is of the same order. 


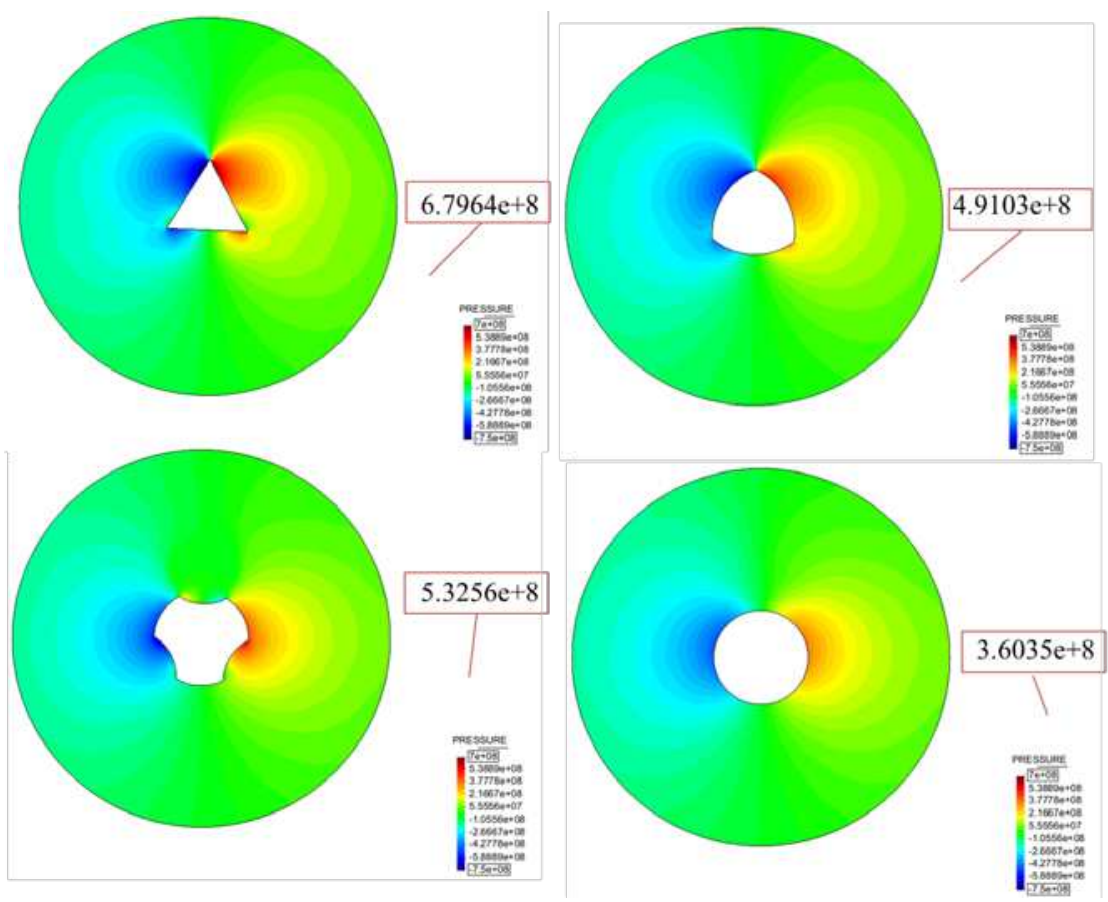

Figure 4: Pressure contour field obtained from different pin shapes

In a next step, the effect of slip condition on the same problem is studied. In this case, the pin rotational velocity has less effect on the work-piece than in the stick case. The triflute and the circular pin lead to considerably different streamlines (Figure 5). The streamlines for a circular pin show a passing flow through an obstacle while for a triflute pin, they show the trapped material in the segments of the pin moving with it. In the slip case, the joint is not qualified even though in the triflute case, the joint is created due to the effect of the segments. In the stick case, the joint is created following the ring patterns observed generally in the FSW process. The effect of the segments can be also seen in the Figure 6 for the slip case as the material close to the pin is affected by the pin velocity. 

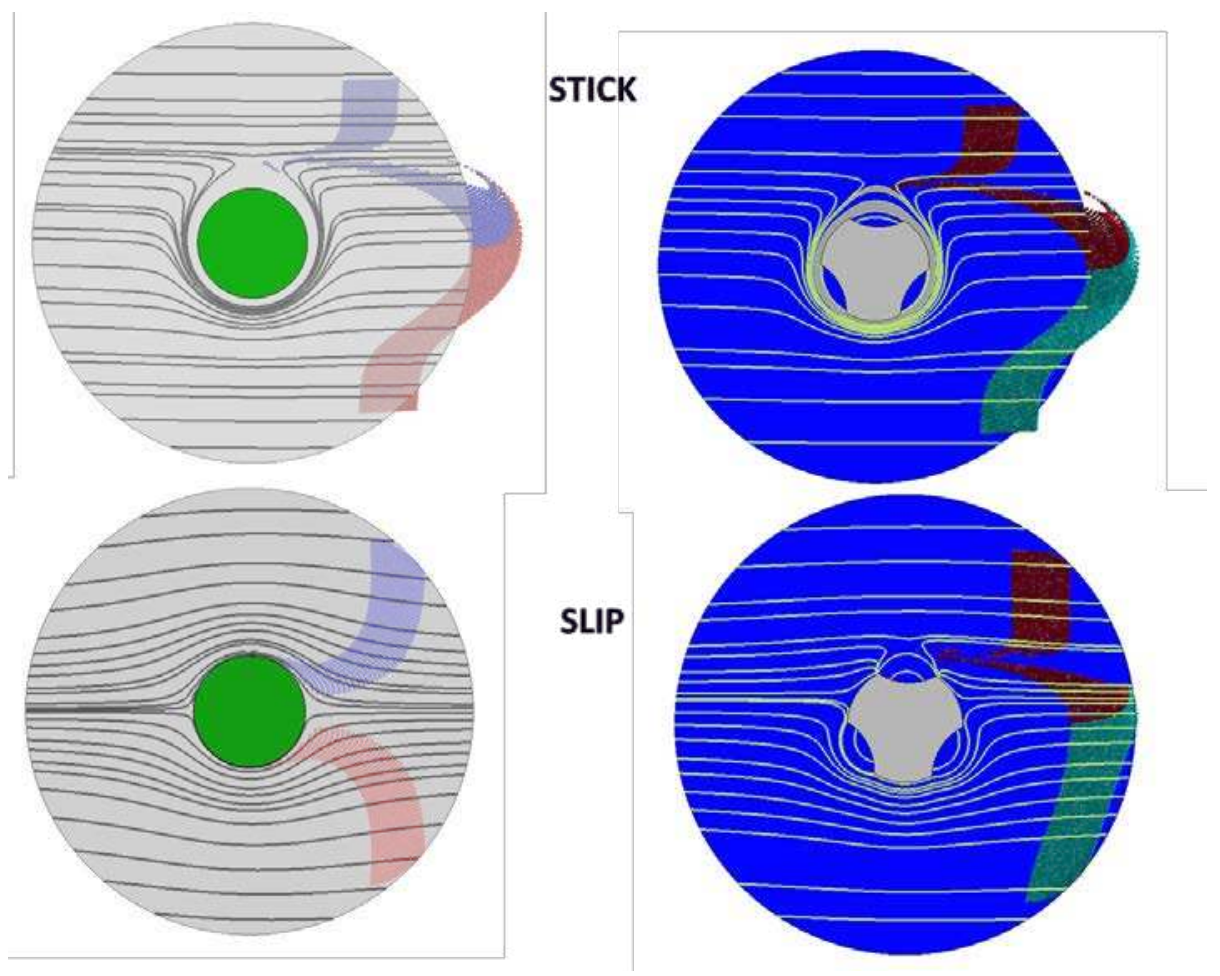

Figure 5: Streamlines and created joints in both the stick and slip cases for circular and triflute pins
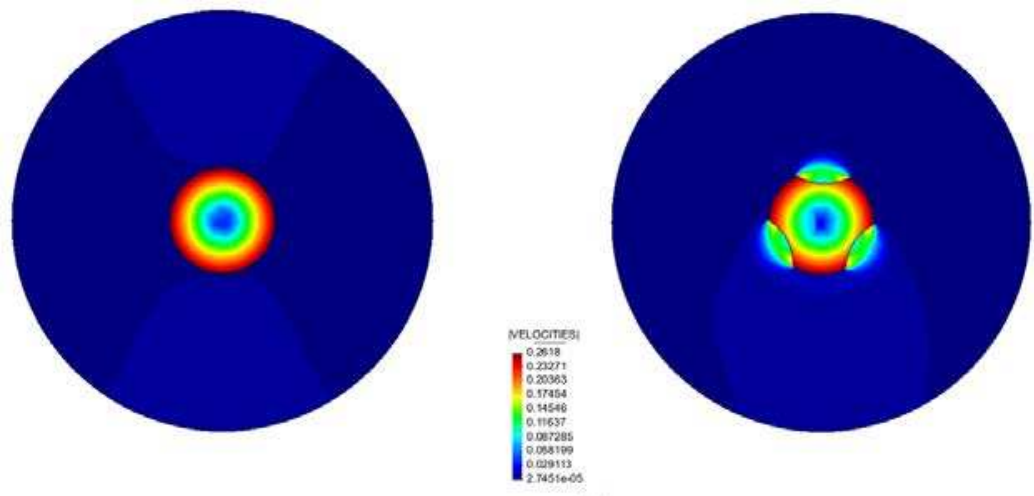

GD

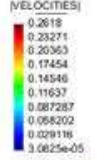

Figure 6: Velocity contour field in the slip case for circular and triflute pins 

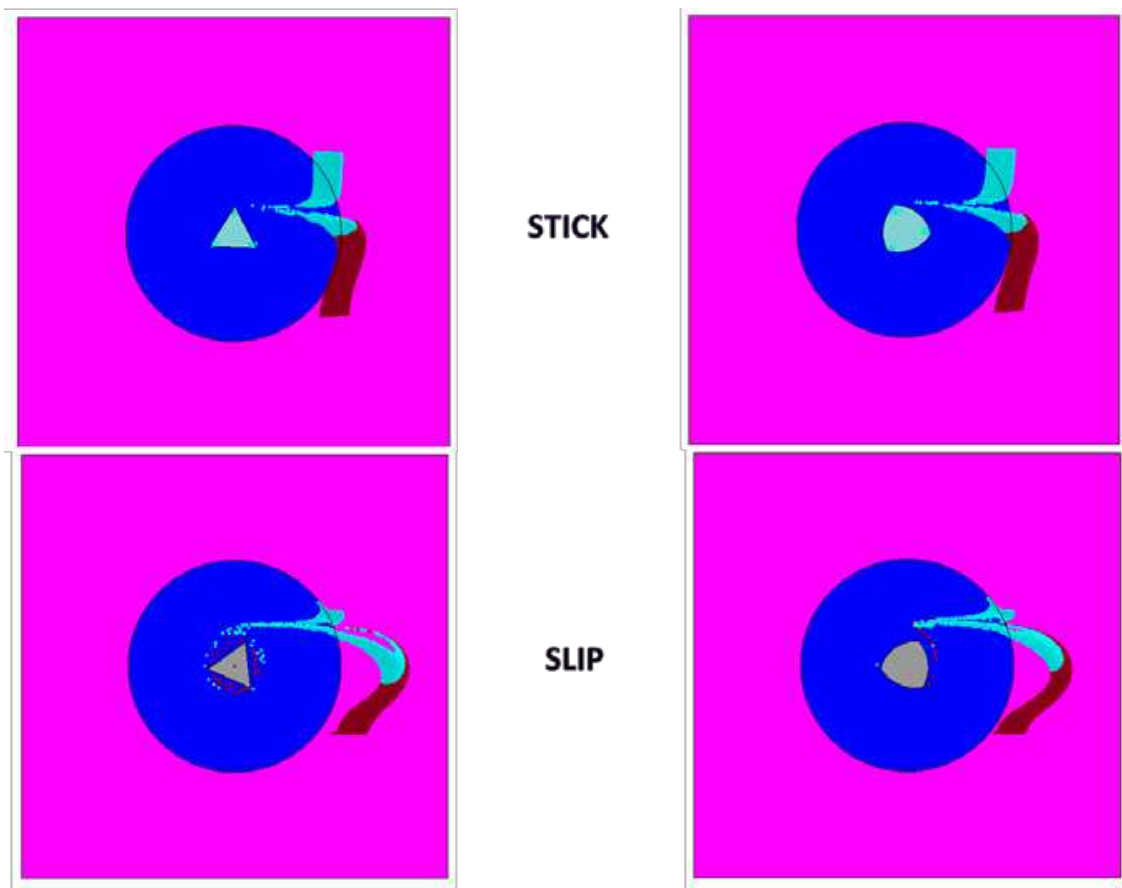

Figure 7: Streamlines and created joints in both the stick and slip cases for triangular and trivex pins
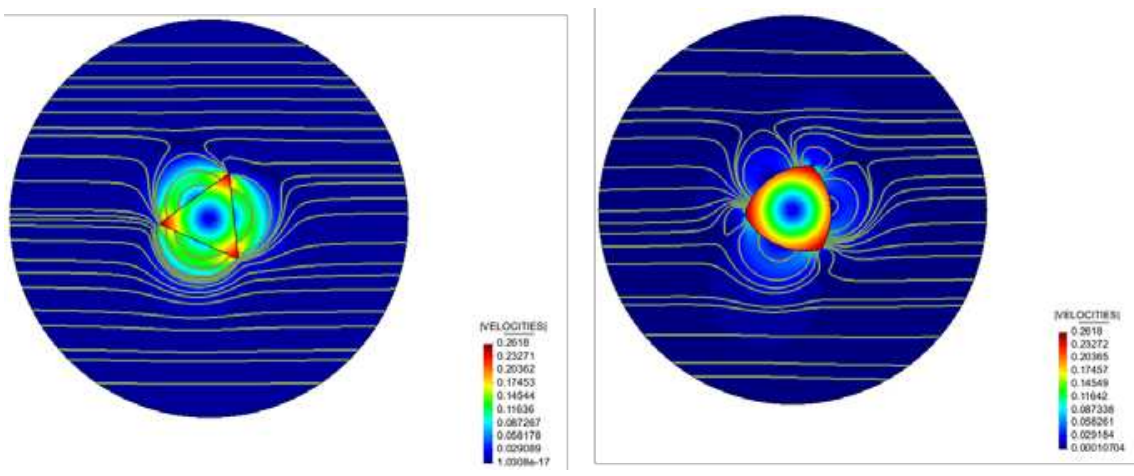

Figure 8: Streamlines and velocity contour field in the slip case for triangular and trivex pins 
Figure 7 shows that for both the slip and stick cases, joints are created using triangular and trivex pins. However, in the stick case, the joint is not qualified and does not follow the usual pattern of FSW due to the void creation. When the slip condition is assumed, the voids are not created. Material around the pin does not share the same velocity as the pin, but it moves due to the non-circular shape (Figure 8) and a qualified joint is created.

It can be concluded that different types of pin shapes can be selected for different conditions of the weld. In stick case, pins without sharp corners create qualified joints while the pins with sharp corners can be used in slip cases.

Material deformed by the friction stir tool must be capable of filling the void produced by a traversing pin. If the tool design is incorrect, the deformed material will cool before the material can fully fill the region directly behind the tool.

The presented results are preliminary, but the proposed method could clearly be of great benefit in reducing experimental trials if near optimal welding conditions could be predicted directly from knowledge of the material joint behavior.

\section{Conclusion}

The work deals with the simulation and visualization of material flow. The simulation of the transient phase is important for understanding the material behavior. The model can provide this insight by computing the particles' thermo-mechanical history. If the process is defined in an ALE/Eulerian setting, an additional method must be introduced in order to find the particles' history. The particle tracing method for the material stirring during and after welding is applied to the material flow visualization of the FSW process. The RK4 integration method is used for the computation of particle trajectories. 
From the ring shape flow pattern left after the welding, it is found that the ratio between the rotational and the advancing speed is one of the key points for the qualified joint creation. The effect of pin shapes on the weld quality is studied. It is found that in the stick case, pins with sharp corners (triangular and trivex) generate voids while this problem does not appears in the slip case. Moreover, the effect of the segments of a triflute pin on the weld quality is studied and shows that the material trapped in the segments moves with the pin in both stick and slip cases.

\section{References}

[1] Thomas W.M., Nicholas E.D., Needham J.C., Murch M.G., Temple-Smith P. and Dawes C.J. (1991) Friction-stir butt welding. GB Patent No. 9125978.8, International Patent No. PCT/GB92 /02203.

[2] London B., Mahoney M., Bingel B., Calabrese R., Waldron D. (2001) Experimental methods for determining material flow in friction stir welds. The Third International Symposium on Friction Stir Welding, Kobe, Japan, 27-28 September.

[3] Reynolds A.P (2008) Flow visualization and simulation in FSW. Scripta Materialia 58:338-342.

[4] Seidel T.U. and Reynolds A.P. (2001) Visualization of the material flow in AA2195 Friction Stir Welds using a marker insert technique. Metallurgical and Materials Transaction A32:2879-2884.

[5] Colligan K. (1999) Material Flow Behaviour during Friction Stir Welding of Aluminium. Welding Journal 78:229-237.

[6] Guerra M., Schmids C., McClure J.C., Murr L.E. and Nunes A.C. (2003) Flow patterns during friction stir welding. Material Characterization 49:95-101.

[7] Dickerson T., Shercliff H.R., Schmidt H. (2003) A weld marker technique for flow visualization in friction stir welding. 4th International Symposium on Friction Stir Welding, Park City, Utah, USA, 14-16 May.

[8] Kallgren T., Jin L.-Z., Sandstrom R. (2008) Material Flow during Friction Stir Welding of Copper. 7th International Friction Stir Welding symposium, Awaji Island, Japan, 20-22 May. 
[9] Johnson R. and Threadgill P. (2003) Friction Stir Welding of Magnesium alloys. Magnesium Technology 2003.

[10] Ouyang J., Yarrapareddy E., Kovacevic R. (2006) Microstructural evolution in the friction stir welded 6061 aluminum alloy (T6-temper condition) to copper. Journal of Materials Processing Technology 172:110-122.

[11] Abdollah-Zadeh A., Saeid T., Sazgari B. (2008) Microstructural and mechanical properties of friction stir welded aluminum/copper lap joints. Journal of Alloys and Compounds 460:535-538.

[12] Buffa G., Fratini L., Micari F. and Shivpuri R. (2008) Material Flow in FSW of T-joints: Experimental and Numerical Analysis. International Journal of Material Forming, 1(1):12831286.

[13] Buffa G., Ducato A. and Fratini L., (2011) Numerical procedure for residual stresses prediction in friction stir welding, Finite Elements in Analysis and Design, 47(4) : 470-476.

[14] Alfaro I., Racineux G., Poitou A., Cueto E. and Chinesta F. (2009) Numerical simulation of friction stir welding by natural elements method. International Journal of Material Forming, 2(4):225-234.

[15] Guerdoux S. and Fourment L. (2009) A 3D numerical simulation of different phases of friction stir welding, Modeling and Simulation in Material Science and Engineering, 17:075001.

[16] Feulvarch E., Roux J.-C. and Bergheau J.-M. (2013) A simple and robust moving mesh technique for the finite element simulation of Friction Stir Welding, Journal of Computational and Applied Mathematics 246:269-277.

[17] Chiumenti M., Cervera M., Agelet de Saracibar C. and Dialami N. (2013) Numerical Modeling of Friction Stir Welding Processes, Computer Methods in Applied Mechanics and Engineering 254:353-369.

[18] Dialami N., Chiumenti M., Cervera M. and Agelet de Saracibar C. (2013) An apropos kinematic framework for the numerical modelling of friction stir welding, Computers and Structures 117:48-57.

[19] Agelet de Saracibar C., Chiumenti M., Cervera M., Dialami N. and Seret A. (2014) Computational modeling and sub-grid scale 
stabilization of incompressibility and convection in the numerical simulation of friction stir welding processes, Archives of Computational Methods in Engineering, 21(1), in press.

[20] Bussetta P., Dialami N., Boman R., Chiumenti M., Agelet de Saracibar C., Cervera M. and Ponthot J.P. (2013) Comparison of a fluid and a solid approach for the numerical simulation of Friction Stir Welding with a non-cylindrical pin, Steel Research International, in press.

[21] Dialami N., Chiumenti M., Cervera M., Agelet de Saracibar C. and Ponthot J.P. (2013) Material Flow Visualization in Friction Stir Welding via Particle Tracing, International Journal of Material Forming, in press. 